\title{
Increased expression of epidermal growth factor receptor and betacellulin during the early stage of gastric ulcer healing
}

\author{
GEUN HAE CHOI, HO SUNG PARK, KYUNG RYOUL KIM, HA NA CHOI, KYU YUN JANG, \\ MYOUNG JA CHUNG, MYOUNG JAE KANG, DONG GEUN LEE and WOO SUNG MOON \\ Department of Pathology, Institute for Medical Sciences, Chonbuk National University Medical School \\ and the Center for Healthcare Technology Development, Jeonju, Korea
}

Received January 2, 2008; Accepted February 22, 2008

\begin{abstract}
Epidermal growth factor receptor (EGFR) is important for the proliferation and differentiation of gastric mucosal cells. Betacellulin (BTC) is a novel ligand for EGFR Since their role is unclear in the ulcer healing process, we investigated their expression. Gastric ulcers in 30 SpragueDawley rats were induced by acetic acid. RT-PCR and Western blotting were performed to detect EGFR and BTC. Immunohistochemical studies were performed to detect EGFR, BTC and proliferating cell nuclear antigen (PCNA). The expression of EGFR and the BTC gene was significantly increased at $12 \mathrm{~h}, 24 \mathrm{~h}$ and 3 days after ulcer induction $(\mathrm{P}<0.05)$. The expression of EGFR and BTC protein was significantly increased at $24 \mathrm{~h}$ and 3 days and at $12 \mathrm{~h}, 24 \mathrm{~h}$ and 3 days after ulcer induction, respectively $(\mathrm{P}<0.05)$. The phosphorylation of EGFR also increased significantly and reached a maximum $24 \mathrm{~h}$ after ulcer induction $(\mathrm{P}<0.05)$. Immunostaining for EGFR and BTC was observed in numerous epithelial cells from the ulcer margin and ulcer bed, and corresponded to the localization of PCNA. To conclude, there was an increase in EGFR and BTC expression in the early stages of ulcer healing, localized in the epithelial cells of the ulcer margins and regenerating glands with proliferating activity. BTC/EGFR may play an important role in the early stages of ulcer healing.
\end{abstract}

\section{Introduction}

Gastric ulcers are defined as a breach in the mucosa that extends through the muscularis mucosae into the submucosa or even deeper (1). Ulcers can be distinguished from erosions, in which there is epithelial disruption within the mucosa but no breach of the muscularis mucosae (1). The ulcer results

Correspondence to: Dr Woo Sung Moon, Department of Pathology, Chonbuk National University Medical School, San 2-20 Geumamdong, Deokjin-gu, Jeonju 561-180, Korea

E-mail:mws@chonbuk.ac.kr

Key words: stomach ulcer, receptor, epidermal growth factor, betacellulin protein, human from tissue necrosis triggered by mucosal ischemia, free radical formation and the cessation of nutrient delivery, which are caused by vascular and microvascular injury such as thrombi, constriction or other occlusions (2). Tissue necrosis and the release of leukotriene B attract leukocytes and macrophages, which release pro-inflammatory cytokines (e.g. TNF $\alpha$, IL-1 $\alpha$, and IL-1ß). These in turn activate local fibroblasts, endothelial and epithelial cells. Histologically, an ulcer has two characteristic structures: a distinct ulcer margin formed by the adjacent non-necrotic mucosa, and granulation tissue composed of fibroblasts, macrophages and proliferating endothelial cells forming microvessels at the ulcer base $(1,3)$ Ulcer healing is a complicated process that involves cell migration, proliferation, re-epithelialization, angiogenesis and matrix deposition, all ultimately leading to scar formation (1-4). The regulatory mechanism of ulcer healing is modulated by growth factors, transcription factors and cytokines (2-5).

The epidermal growth factor (EGF) family and growth factors with structural similarity to EGF have been detected in the normal human gastric mucosa (6-9). They bind to their specific cell surface receptor, EGF receptor (EGFR), which has intrinsic tyrosine kinase activity. EGRF can be activated by the binding of its ligands, including EGF (10), transforming growth factor- $\alpha$ (TGF- $\alpha$ ) (11), heparin-binding EGF-like growth factor (HB-EGF) (12), amphiregulin (AR) (8), betacellulin (BTC) (13) and epiregulin (14). The effects of these growth factors are pleiotropic, ranging from the induction of DNA synthesis and changes in cell adhesion and motility to the stimulation of the differentiated cell function (15). In particular, EGF $(10,16)$ as well as TGF- $\alpha$ (17) play important roles in the proliferation and differentiation of mucosal cells in the gastrointestinal tract, including the stomach. In addition, several studies have demonstrated that EGF and EGFR are overexpressed in the epithelial cells in the ulcer margin during ulcer healing, which requires epithelial migration and proliferation (18-20).

BTC is a $32-\mathrm{kDa}$ glycoprotein, synthesized as a large transmembrane precursor molecule, which can be cleaved proteolytically to the soluble form of BTC. It functions as a membraneanchored growth factor in paracrine signaling, and was originally identified as a growth-promoting factor in the conditioned medium of a mouse and human pancreatic B-cell carcinoma (insulinoma) cell line $(13,21)$. To date, BTC has been shown to be a potent mitogen for fibroblasts, vascular 
smooth muscle cells and retinal pigment epithelial cells. It is synthesized in a wide variety of adult tissues, including the liver, kidney, lung, small intestine and colon and in many cultured cells, including smooth muscle cells and epithelial cells $(13,21)$. We hypothesized that BTC may also play an important role in the gastric ulcer healing process because EGFR and its ligands, EGF and TGF- $\alpha$, are involved in gastric ulcer healing and BTC is one of the EGFR ligands. BTC has a proliferative effect on fibroblasts and vascular smooth muscle cells, which are characteristic features of ulcer healing.

Therefore, this study examined i) the level of EGFR and BTC expression in the gastric ulcer and ii) activation of EGFR during gastric ulcer healing. In addition, an immunohistochemical study was performed to determine the distribution of EGFR and BTC in rat gastric ulcer tissue as well as to evaluate the relationship between cell proliferation and expression of EGFR and BTC in rat gastric mucosa.

\section{Materials and methods}

Induction of chronic gastric ulcers by acetic acid. The Subcommittee for Animal Studies of the Chonbuk National University Medical School (Jeonju, Korea) approved this study. Thirty male Sprague-Dawley rats (Samtako, Osan, Korea) weighing 220-250 g were used in the experiments. The rats were fasted for $16 \mathrm{~h}$ before undergoing a laparotomy under pentobarbital anesthesia (50 mg/kg body weight, administered intraperitoneally). The gastric ulcers were induced by the topical application of $100 \%$ acetic acid $(50 \mu 1)$ through a polyethylene tube (4-mm inner diameter) to the anterior wall of the stomach for $60 \mathrm{sec}$. The area was then washed with phosphate-buffered saline (PBS), and the abdomen was closed. The control rats $(n=4)$ underwent the operation as described above without the application of acetic acid (sham operation). The rats were sacrificed at $12 \mathrm{~h}, 24 \mathrm{~h}$, 3 days, 7 days or 14 days after ulcer induction. The anterior wall of the stomach including the ulcer was excised, rinsed in PBS, snap-frozen in liquid nitrogen for the extraction of RNA and protein, or fixed in $10 \%$ formalin for immunohistochemical staining.

Determination of EGFR and BTC $m R N A$ by RT-PCR. Reverse transcription polymerase chain reaction (RT-PCR) was carried out to determine the levels of EGFR and BTC mRNA in the rat gastric ulcer tissues using a GeneAmp RNA-PCR Kit and a DNA thermal cycler (Perkin-Elmer, Foster, CA). The RNA was isolated using an Ultra-Turrax homogenizer (Ika, Staufen, Germany) and TRIzol Reagent (Invitrogen, Carlsbad, CA) according to the manufacturer's instructions. The quality of the isolated RNA was verified by electrophoresis on $1 \%$ agarose-formaldehyde gels, and its quantity was determined by measuring its absorbance at 260 and $280 \mathrm{~nm}$. Total-RNA $(5 \mu \mathrm{g})$ was used as the template to synthesize the complementary DNA (cDNA) with the Moloney murine leukemia virus (M-MLV, USB, Cleveland, $\mathrm{OH}$ ) in $10 \mu \mathrm{l}$ of buffer containing $10 \mathrm{mM}$ Tris- $\mathrm{HCl}, 50 \mathrm{mM} \mathrm{KCl}, 1 \mathrm{mM}$ dNTP and $5 \mathrm{mM}$ random hexamers. RT was performed for $1 \mathrm{~h}$ at $42^{\circ} \mathrm{C}$, followed by $10 \mathrm{~min}$ at $95^{\circ} \mathrm{C}$ to denature the enzyme. The resulting cDNA $(2 \mu \mathrm{g})$ was used as a template for the subsequent PCR. The specific primer set for EGFR was
5'-CAACCCTGAGTATCTCAACA-3' (sense) and 5'-CTG GAAAGTCCGGTTTGTAA-3' (antisense). The specific primer set for BTC was 5'-CTTCGTGGTGGACGAGCAA-3' (sense) and 5'-AGCAGACCACCAGGATCTGC-3' (antisense). The sizes of the amplified fragments were $260 \mathrm{bp}$ for EGFR and 122 bp for BTC, respectively. B-actin was used as the loading control for PCR. Thirty cycles of the following were carried out for the amplification of the cDNAs of EGFR and BTC: $5 \mathrm{~min}$ at $95^{\circ} \mathrm{C}$ for initial denaturing, $30 \mathrm{sec}$ at $55^{\circ} \mathrm{C}$ for annealing, $60 \mathrm{sec}$ at $72^{\circ} \mathrm{C}$ for extension, $30 \mathrm{sec}$ at $95^{\circ} \mathrm{C}$ for denaturing, and $10 \mathrm{~min}$ at $72^{\circ} \mathrm{C}$ for a final extension. All experiments were carried out using the conditions optimized for linear amplification. The PCR products were then subjected to electrophoresis on a $1 \%$ agarose gel with ethidium bromide. A luminescent image analyzer (LAS-3000, Fuji, Tokyo, Japan) and Multigauge software V3.0 (Fuji, Tokyo, Japan) were used to make a quantitative assessment of the PCR products. The results were expressed as the target cDNA/ $\beta$-actin ratio.

Protein extraction and determination of EGFR, BTC and phospho-EGFR protein levels by Western blotting. The tissues were homogenized using an Ultra-Turrax homogenizer in an ice-cold lysis buffer containing $50 \mathrm{mM}$ Tris ( $\mathrm{pH} 7.5), 150 \mathrm{mM}$ $\mathrm{NaCl}, 0.5 \%$ Nonidet $\mathrm{p}-40,1 \mathrm{mM}$ phenylmethylsulfonyl fluoride, $2 \mu \mathrm{g} / \mathrm{ml}$ leupeptin, $2 \mu \mathrm{g} / \mathrm{ml}$ aprotinin, $5 \mathrm{mM}$ sodium fluoride and $1 \mathrm{mM}$ sodium orthovanadate. The homogenates were then centrifuged at $14,000 \mathrm{rpm}$ for $10 \mathrm{~min}$ at $4^{\circ} \mathrm{C}$. The protein concentration in the supernatant was determined using a protein assay reagent kit (Pierce, Rockford, IL). Equal amounts of protein $(50 \mu \mathrm{g})$ were subjected to sodium dodecyl sulphate-polyacrylamide gel electrophoresis and transferred to polyvinylidene difluoride membranes (Millipore, Bedford, MA). The membranes were incubated at $4{ }^{\circ} \mathrm{C}$ overnight with EGFR (Sigma, St. Louis, MO), phospho-EGFR (Cell Signaling, Danvers, MA) and BTC (Santa Cruz Biotechnology, Santa Cruz, CA) antibodies, then washed and incubated with the corresponding anti-IgG peroxidase conjugates at room temperature for $1 \mathrm{~h}$. The signal of the bound antibodies was visualized by chemi-luminescence (Amersham Bioscience, Buckinghamshire, UK). The membranes were stripped and reprobed with the monoclonal anti- $\beta$-actin antibody (Sigma) as a control for the protein loading and transfer. The data was quantified using a luminescent image analyzer.

Determination of EGFR, BTC and proliferating cell nuclear antigen expression by immunohistochemical staining. Immunohistochemical staining with anti-EGFR, anti-BTC and anti-proliferating cell nuclear antigen (PCNA) antibodies was carried out to determine their expression in the gastric ulcers. Briefly, after deparaffinization, the tissue sections underwent a microwave antigen retrieval procedure in $0.01 \mathrm{M}$ sodium citrate buffer ( $\mathrm{pH}$ 6.0) for $10 \mathrm{~min}$. After blocking the endogenous peroxidase, non-specific staining was blocked by incubating the sections with Protein Block Serum-Free (Dako, Carpinteria, CA) at room temperature for $10 \mathrm{~min}$. The sections were then incubated with anti-BTC $(1: 100$, Santa Cruz Biotechnology), anti-EGFR (1:1000, Sigma) and anti-PCNA (1:50, Dako) antibodies for $2 \mathrm{~h}$ at room temperature. After washing, the sections were incubated for $30 \mathrm{~min}$ with biotin- 
A
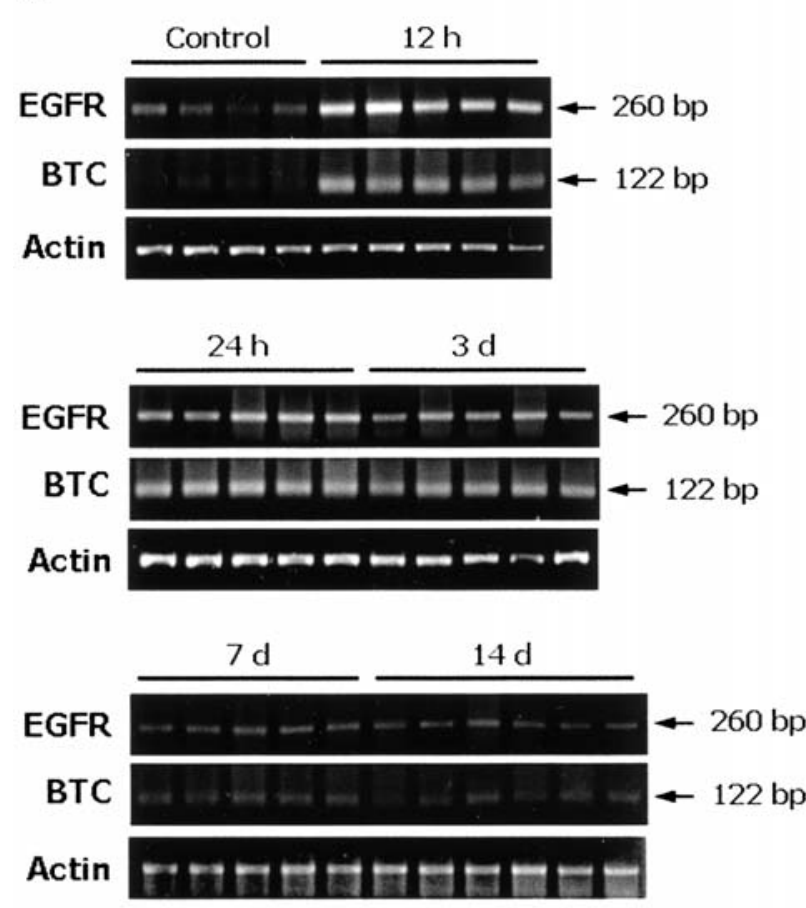

B

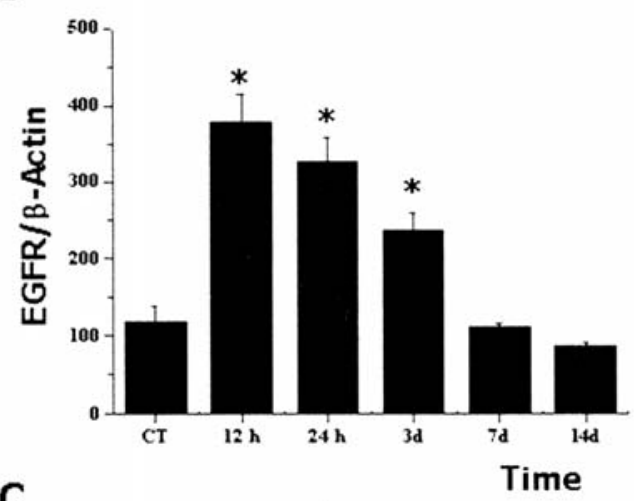

C

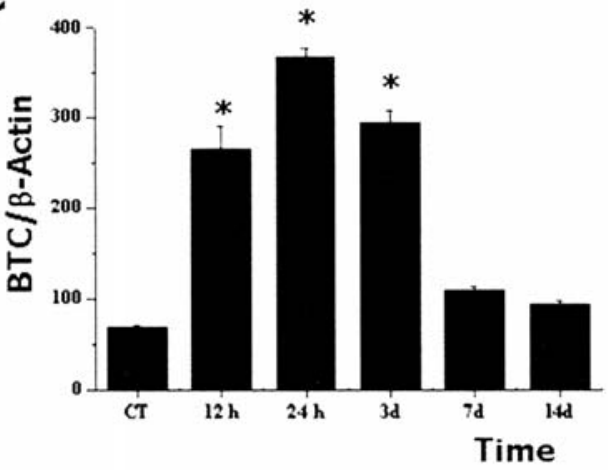

Figure 1. Time course changes of EGFR and BTC mRNA expression in experimental gastric ulcer. (A) RT-PCR products were obtained using the specific primers for EGFR (260 bp), BTC (122 bp) and B-actin. Quantitative data for the mRNA expression of EGFR (B) and BTC (C). Data were obtained by computerized analysis of the optical intensity of the amplified PCR products. Each signal was normalized against the corresponding $\beta$-actin signal. Results are expressed as the EGFR/ß-actin and BTC/ß-actin ratios, and are represented as the mean $\pm \mathrm{SE}$. ${ }^{*} \mathrm{P}<0.05$ versus the control.

conjugated IgG and for $30 \mathrm{~min}$ with peroxidase-conjugated streptavidin at room temperature. The peroxidase activity was detected using the enzyme substrate 3-amino-9-ethyl carbazole.

Statistical analysis. Values were expressed as the mean $\pm \mathrm{SE}$. The one-way ANOVA test was used to determine the statistical significance of the differences between the control and ulcer tissues with time. A P-value $<0.05$ was considered significant.

\section{Results}

Time course changes of EGFR and BTC mRNA expression in gastric ulcers. EGFR is required for gastric ulcer healing and BTC is a novel ligand for EGFR. The time course of the changes in mRNA expression of EGFR and BTC was examined by RT-PCR. The EGFR mRNA level of the ulcer group $12 \mathrm{~h}, 24 \mathrm{~h}$ and 3 days after ulcer induction was significantly increased compared with that of the control group $(\mathrm{P}<0.05)$ (Fig. 1). In the ulcer group, EGFR expression reached a maximum at $12 \mathrm{~h}$ and declined thereafter in a timedependent manner, but remained higher than that of the control until day 3. The level of BTC gene expression was also significantly higher in the ulcer group at $12 \mathrm{~h}, 24 \mathrm{~h}$ and 3 days than in the control $(\mathrm{P}<0.05)$. BTC expression reached a maximum at $24 \mathrm{~h}$ and declined thereafter in a time-dependent manner, but also remained higher than that of the control until day 3. These results suggest that EGFR and BTC may be involved in the early stages of ulcer healing.
Time course changes of EGFR and phospho-EGFR protein expression in gastric ulcers. The time course changes of the protein expression of EGFR and phospho-EGFR in the gastric ulcer were examined using Western blotting. As shown in Fig. 2, EGFR protein expression began to increase at $12 \mathrm{~h}$ after ulcer induction and reached significant levels at $24 \mathrm{~h}$ and 3 days $(\mathrm{P}<0.05)$. The level of EGFR protein expression reached a maximum at $24 \mathrm{~h}$ and declined thereafter. The phosphorylation of EGFR began to increase at $12 \mathrm{~h}$ after ulcer induction and reached significant levels at $24 \mathrm{~h}(\mathrm{P}<0.05)$ and declined thereafter. These results show that the expression of the EGFR protein and its phosphorylation reached a maximum within $24 \mathrm{~h}$, which is regarded as the early stages of ulcer healing.

Time course changes of BTC protein expression in gastric ulcers. Since increased expression of the BTC gene was observed after ulcer induction, the time course changes in the expression of BTC protein during ulcer healing were examined using Western blotting. As shown in Fig. 2, the level of BTC protein was significantly higher in the ulcer group than in the control at $12 \mathrm{~h}, 24 \mathrm{~h}$ and 3 days after ulcer induction $(\mathrm{P}<0.05)$, and reached a maximum level at $24 \mathrm{~h}$. From day 7 to 14 , the expression of the BTC protein decreased markedly.

EGFR, BTC and PCNA immunohistochemistry in rat gastric ulcers. To examine EGFR and BTC localization during ulcer healing, the level of EGFR and BTC expression in formalinfixed paraffin-embedded gastric tissue sections was determined 
A

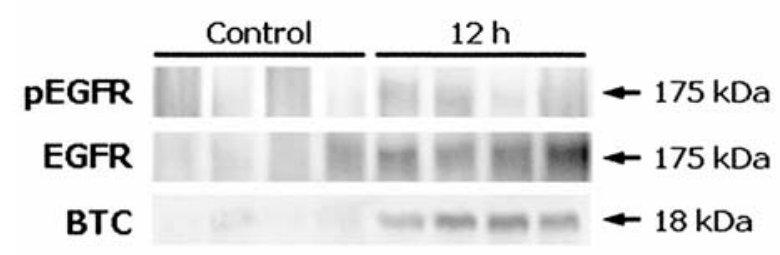

Actin -2
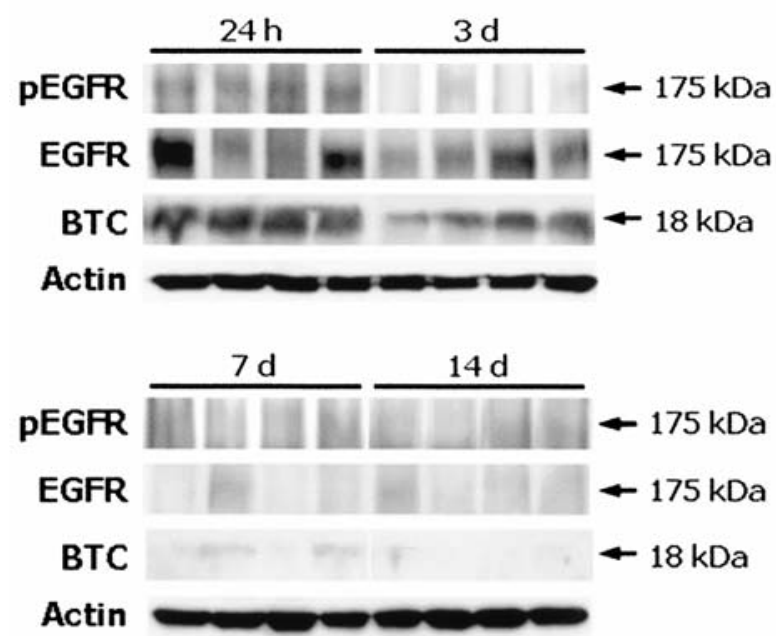

B

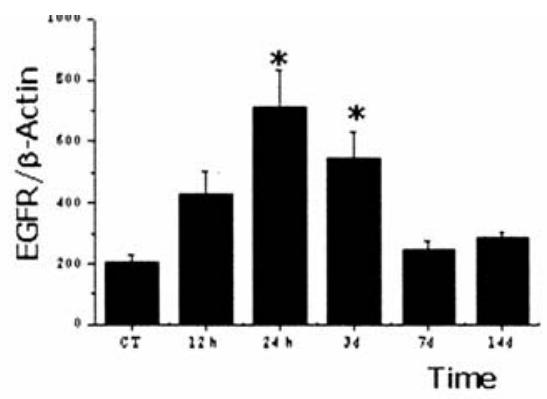

C

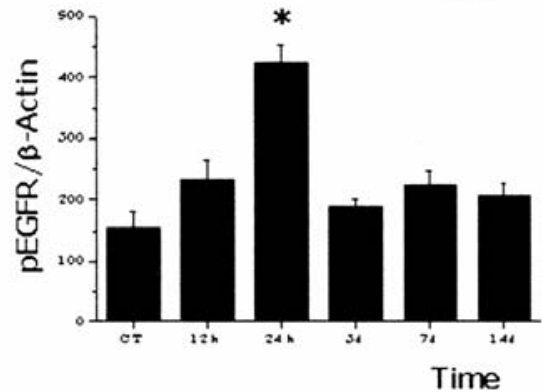

D

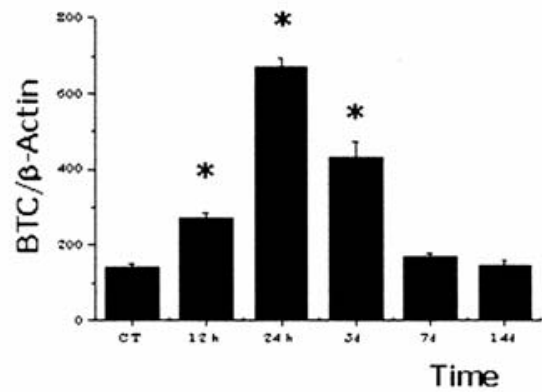

Figure 2. Time course changes in the protein expression of EGFR, phospho-EGFR and BTC in an experimental gastric ulcer. (A) Immunoblotting with the specific antibodies detected the specific 175-kDa band for EGFR and the 18-kDa band for BTC. The phosphorylation of EGFR was detected by the phosphoEGFR antibody. Quantitative data of the protein expression for EGFR (B), phospho-EGFR (C) and BTC (D). The data was obtained by computerized analysis of the Western blots. Each signal was normalized to the corresponding B-actin signal. Results are expressed as the EGFR/B-actin, phospho-EGFR/B-actin and $\mathrm{BTC} / \beta$-actin ratios, and are represented as the mean $\pm \mathrm{SE} .{ }^{*} \mathrm{P}<0.05$ versus the control.

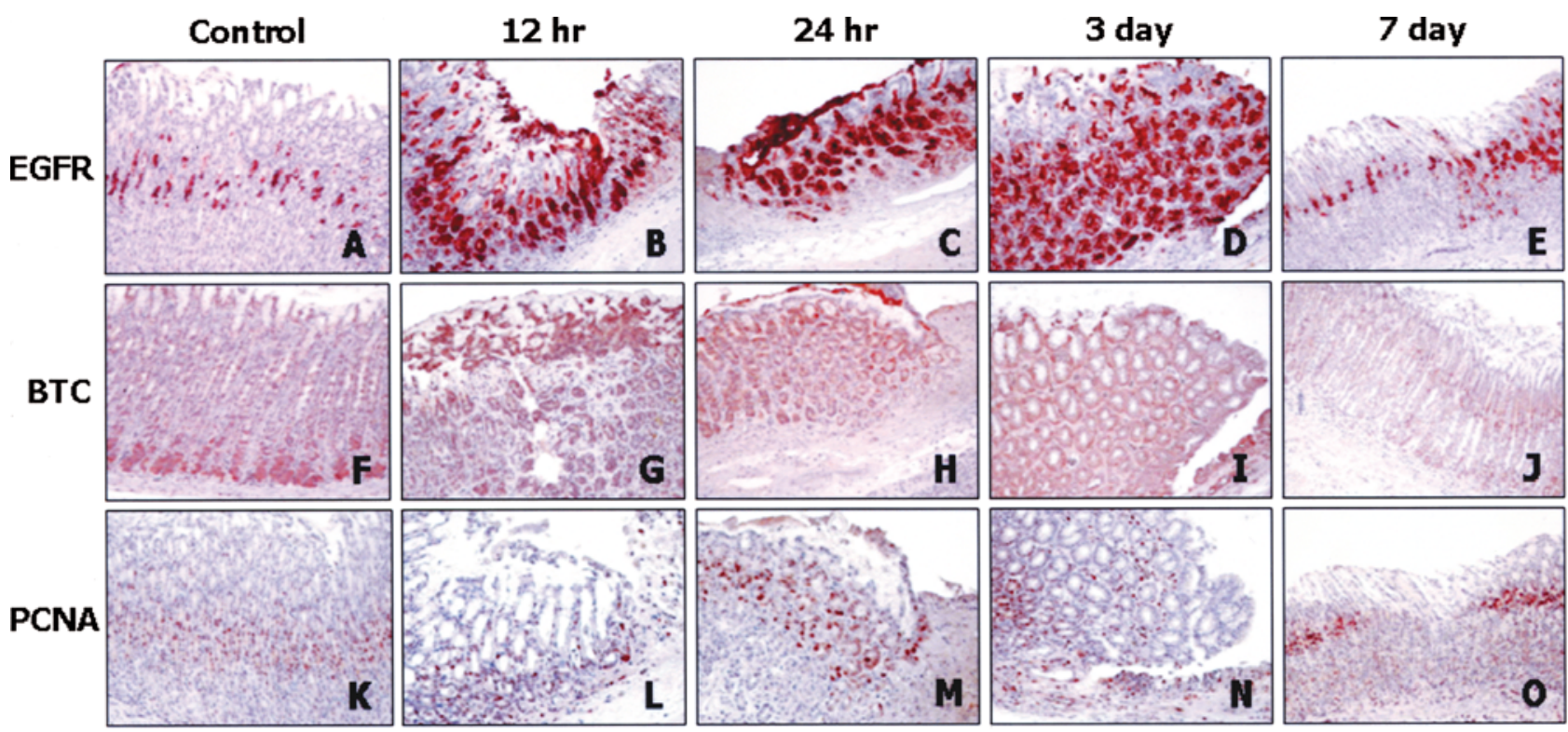

Figure 3. The localization of EGFR (A-E), BTC (F-J) and PCNA (K-O) in the experimental gastric ulcer determined by immunohistochemistry. In the normal gastric tissue, EGFR (A) was mainly localized in mucous neck cells of the proliferation zone, whereas BTC (F) was mainly localized in the base of the gastric mucosa. From 12 to $24 \mathrm{~h}$ after ulcer induction, EGFR (B and C) was present in the epithelial cells of the ulcer margin and the ulcer bed, whereas BTC (G and H) was diffusely localized in epithelial cells and the ulcer margin. At day 3, EGFR (D) and BTC (I) were observed in the epithelial cells lining the regenerating gastric glands, but the intensity was weaker than that observed at 12 and $24 \mathrm{~h}$. At day 7, EGFR (E) and BTC (J) were mainly localized in the mucous neck cells of the proliferation zone. The areas expressing PCNA (K-O) also expressed EGFR and BTC at the same time points. (Magnification of the control up to day $3, \mathrm{x} 100$; at day $7, \mathrm{x} 40$ ). 
by immunohistochemistry. As shown in Fig. 3, EGFR was mainly localized in some mucous neck cells of the proliferation zone in normal gastric mucosa. EGFR expression was also observed in some parietal cells, but was weaker than in the neck cells. On the other hand, BTC was mainly localized in the base of the gastric mucosa in normal gastric tissue (Fig. 3). From 12 to $24 \mathrm{~h}$ after ulcer induction, EGFR immunoreactivity was diffuse and strong in the mucosa of the ulcer margin and ulcer bed. At this time, BTC was diffusely localized in the epithelial cells of the ulcer margin. Three days after ulcer induction, EGFR immunoreactivity was observed in the epithelial cells lining the regenerating gastric glands, but the staining intensity was weaker than that observed at 12 and $24 \mathrm{~h}$. At this time, the immunoreactivity of BTC was also localized in the epithelial cells lining the regenerating gastric glands with weaker staining intensity. Seven days after ulcer induction, the immunoreactivity of EGFR was mainly localized in the mucous neck cells of the proliferation zone, as well as in the regenerating gastric glands in the ulcer scars. At this time, BTC was localized mainly in the mucous neck cells of the proliferation zone and at the base of the gastric mucosa.

Localization of the proliferating activity was determined by immunohistochemistry for PCNA and was compared with the areas expressing EGFR and BTC in the same specimens. As shown in Fig. 3, the areas expressing PCNA were similar to those expressing EGFR and BTC. These findings suggest a positive relationship between levels of EGFR and BTC expression and proliferating activity.

\section{Discussion}

An ulcer is a deep defect in the esophageal, gastric, duodenal or intestinal wall that involves the entire mucosal thickness and penetrates the muscularis mucosae. Ulcer healing is an active and complex process that requires the coordinated interaction of various cellular and connective tissue components. In addition, ulcer healing involves the reconstruction of the glandular structures, the re-epithelialization of the mucosal surface, angiogenesis, and the estoration of connective tissue components (3). During ulcer healing, processes including mucosal cell migration, proliferation and biochemical events are modulated by various growth factors, transcription factors and cytokines (2-5).

Previous studies have shown that a number of growth factors, including EGF, TGF- $\alpha$, trefoil growth peptides and bFGF, participate in the repair of tissue injury by stimulating cell proliferation and migration, an essential step for reepithelialization and ulcer healing $(18,20,22-25)$. Gastric ulceration also induces the overexpression of EGF and its receptor EGFR $(18,22)$.

EGFR is a $170-\mathrm{kDa}$ receptor tyrosine kinase that has been detected in a variety of tissues and cells (6-9). The EGFR family includes four homologous transmembrane receptor protein kinases, EGFR, c-erbB-2, c-erbB-3 and c-erbB-4. This receptor family plays an important role in regulating cell proliferation, differentiation and transformation $(24,25)$. EGFR binds several ligands, including EGF, TGF- $\alpha$, HB-EGF, AR, BTC and epiregulin (10-14). Binding affinities vary among these ligands. Ligand-induced activation of these receptors results in the formation of homodimers and heterodimers, which undergo transphosphorylation and transactivation $(26,27)$. It has been reported that EGFR is involved in organ morphogenesis, the maintenance and repair of tissues, and epithelial migration and proliferation (18-20). This study examined the time course change of EGFR mRNA and protein expression in gastric tissue after ulcer induction. The results show that expression of EGFR mRNA and protein reached a maximum level at 12 and $24 \mathrm{~h}$, respectively. In addition, the level of EGFR phosphorylation also began to increase at $12 \mathrm{~h}$ and reached a maximum at $24 \mathrm{~h}$ after ulcer induction. Overall, EGFR may play an important role in the early stages of ulcer healing due to its maximal expression and phosphorylation occurring within $24 \mathrm{~h}$ after ulcer induction. These results are consistent with previous studies showing the increase in EGFR expression in the ulcer healing process (18-20).

BTC is a member of the EGF family that binds to EGFR with a similar affinity to EGF. Its soluble active forms are produced by proteolytic cleavage, and it functions as a potent mitogen factor for fibroblasts, vascular smooth muscle cells and retinal pigment epithelial cells (13). It was reported that BTC induces proliferation and migration of vascular smooth muscle cell through various signal transduction pathways, including ERK 1/2, Akt and p38 MAPK (28), and that it is synthesized in a wide range of adult tissues, including the liver, kidney, lung, small intestine and colon $(13,21)$. Because EGFR and its ligands, EGF and TGF- $\alpha$, play an important role in gastric ulcer healing through the migration and proliferation of epithelial cells, it could be assumed that BTC is also involved in the ulcer healing process. However, there have been no reports on this hypothesis. Therefore, this study undertook to examine whether or not the expression of BTC in gastric tissue is altered after ulcer induction. The results show that the expression of both the mRNA and protein of BTC reached a maximum level at $24 \mathrm{~h}$. Thus, due to their similar mRNA and protein expression patterns, both BTC and EGFR appear to play important roles in the early stages of gastric ulcer healing.

The time course changes in the in vivo localization of EGFR and BTC expression in gastric ulcer tissue using immunohistochemistry were significant. After the stomach was treated with acetic acid, the gastric walls showed characteristic sequential morphological changes as reported previously (29). Ulcer craters without necrotic tissue developed within 2 days after ulcer induction, and the gastric mucosa of the ulcer margin formed a transitional (or healing) zone by day 3 (20). Seven days after ulcer induction, the size of the ulcer had decreased and its margin was more clearly delineated. In normal gastric tissues, EGFR and BTC expression was mainly localized in the mucous neck cells and the base of the gastric mucosa, respectively. At 12 and $24 \mathrm{~h}$ after ulcer induction, immunoreactivities for EGFR and BTC were diffusely and strongly localized in the numerous epithelial cells lining the gastric glands of the ulcer margin and in the base. The results also show that the localization of EGFR and BTC at day 3 after ulcer induction was similar to that observed at 12 and $24 \mathrm{~h}$, but with weak staining intensity. These results are consistent with those of RT-PCR and Western blotting. In addition, the question of whether increased expression of EGFR and BTC in ulcer healing is involved in mucosa cell proliferation was examined using immunohistochemistry for PCNA. The results 
indicate a positive correlation between increased EGFR and BTC expression in ulcer healing and the proliferation of gastric epithelial cells.

In summary, this study demonstrated for the first time that gastric ulceration triggers an increase in the mRNA and protein expression of EGFR and BTC in the early stages of ulcer healing. EGFR and BTC mRNAs were overexpressed as early as $12 \mathrm{~h}$ after ulcer induction, which lasted for 3 days. Moreover, the cells overexpressing EGFR and BTC had high proliferating activity. Immunohistochemical staining revealed that the epithelial cells in the ulcer margin overexpressed BTC and its receptor EGFR. These cells are major targets for the proliferation-stimulating action of BTC. Therefore BTC, a member of the EGFR ligands, may play an important role in the early stages of ulcer healing. However, further studies are needed to clarify its precise role as a mitogenic factor in ulcer healing.

\section{Acknowledgements}

This work was supported by a Korea Research Foundation Grant funded by the Korean Government (MOEHRD) (The Center for Healthcare Technology Development, Chonbuk National University, Jeonju 561-756, Korea).

\section{References}

1. Lie C and Crawford JM: Peptic ulcer disease. In: Robbins and Cotran Pathologic Basis of Disease. Kumar V, Abbas A and Fausto N (eds). Saunders, Philadelphia, pp816-820, 2005.

2. Tarnawski A, Hollander D, Stachura J, Krause WJ, Eltorai M, Dabros W and Gerqely H: Vascular and microvascular changes - key factors in the development of acetic acid-induced gastric ulcers in rats. J Clin Gastroenterol 12 (Suppl 1): 148-157, 1990.

3. Tarnawski AS: Cellular and molecular mechanisms of gastrointestinal ulcer healing. Dig Dis Sci 50 (suppl 1): 24-33, 2005.

4. Vanwijck R: Surgical biology of wound healing. Bull Mem Acad R Med Belg 156: 175-184, 2001.

5. Taupin D, Wu DC, Jeon WK, Devaney K, Wang TC and Podolsky DK: The trefoil gene family are coordinately expressed immediate-early genes: EGF receptor- and MAP kinasedependent interregulation. J Clin Invest 103: 31-38, 1999.

6. Abe S, Sasano H, Katoh K, et al: Immunohistochemical studies on EGF family growth factors in normal and ulcerated human gastric mucosa. Dig Dis Sci 42: 1199-1209, 1997.

7. Orsini B, Calabro A, Milani S, Grappone C, Herbst H and Surrenti C: Localization of epidermal growth factor/ transforming growth factor-alpha receptor in the human gastric mucosa. An immunohistochemical and in situ hybridization study. Virchows Arch A Pathol Anat Histopathol 423: 57-63, 1993.

8. Shoyab M, Plowman GD, McDonald VL, Bradley JG and Todaro GJ: Structure and function of human amphiregulin: a member of the epidermal growth factor family. Science 243: 1074-1076, 1989.

9. Jones MK, Tomikawa M, Mohajer B and Tarnawski AS: Gastrointestinal mucosal regeneration: role of growth factors. Front Biosci 4: D303-D309, 1999.
10. Tarnawski AS and Jones MK: The role of epidermal growth factor (EGF) and its receptor in mucosal protection, adaptation to injury, and ulcer healing: involvement of EGF-R signal transduction pathways. J Clin Gastroenterol 27 (Suppl 1): 12-20, 1998.

11. Konturek PC, Konturek SJ, Brzozowski T and Ernst H: Epidermal growth factor and transforming growth factor-alpha: role in protection and healing of gastric mucosal lesions. Eur $\mathbf{J}$ Gastroenterol Hepatol 7: 933-937, 1995.

12. Higashiyama S, Lau K, Besner GE, Abraham JA and Klagsbrun M Structure of heparin-binding EGF-like growth factor. J Biol Chem 267: 6205-6212, 1991.

13. Lopez-Torrejon I, Querol E, Aviles FX, Seno M, De Llorens R and Oliva B: Human betacellulin structure modeled from other members of EGF family. J Mol Model 8: 131-144, 2002.

14. Sasaki E, Arakawa T, Fujiwara Y, et al: Epiregulin stimulates proliferation of rabbit gastric cells in primary culture through autophosphorylation of the epidermal growth factor receptor. Eur J Pharmacol 338: 253-258, 1997.

15. Carpenter G and Wahl MI: The epidermal growth factor family. In: Peptide Growth Factors and Their Receptors. Sporn MB and Roberts AB (eds). Springer-Verlag, New York, pp69-171, 1991.

16. Konturek JW, Brzozowski T and Konturek SJ: Epidermal growth factor in protection, repair, and healing of gastroduodenal mucosa. J Clin Gastroenterol 13 (Suppl 1): 88-97, 1991.

17. Konturek SJ, Brzozowski T, Majka J, Dembinski A, Slomiany A and Slomiany BL: Transforming growth factor alpha and epidermal growth factor in protection and healing of gastric mucosal injury. Scand J Gastroenterol 27: 649-655, 1992.

18. Konturek PC, Brzozowski T, Konturek SJ, Ernst H, Drozdowicz D, Pajdo R and Hahn EG: Expression of epidermal growth factor and transforming growth factor alpha during ulcer healing. Time sequence study. Scand J Gastroenterol 32: 6-15, 1997.

19. Lee H, Hansson HA, Norstrom E and Helander HF: Immunoreactivities for epidermal growth factor (EGF) and for EGF receptors in rats with gastric ulcers. Cell Tissue Res 265: 211-218, 1991.

20. Tarnawski A, Stachura J, Durbin T, Sarfeh IJ and Gergely H: Increased expression of epidermal growth factor receptor during gastric ulcer healing in rats. Gastroenterology 102: 695-698, 1992.

21. Dunbar AJ and Goddard C: Structure-function and biological role of betacellulin. Int J Biochem Cell Biol 32: 805-815, 2000.

22. Szabo S and Vincze A: Growth factors in ulcer healing: lessons from recent studies. J Physiol Paris 94: 77-81, 2000.

23. Barnard JA and McHugh KM: Growth factors in the gastrointestinal tract. In: Physiology of the Gastrointestinal Tract. Johnson LR, Barrett KE, Ghishan FK, Merchant JL, Said HM and Wood JD (eds). Academic Press, San Diego, pp183-246, 2006.

24. Barnard JA, Beauchamp RD, Russell WE, Dubois RN and Coffey RJ: Epidermal growth factor-related peptides and their relevance to gastrointestinal pathophysiology. Gastroenterology 108: 564-580, 1995.

25. Cantley LC, Auger KR, Carpenter C, Duckworth B, Graziani A, Kapeller $\mathrm{R}$ and Soltoff $\mathrm{S}$ : Oncogenes and signal transduction. Cell 64: 281-302, 1991.

26. Hackel PO, Zwick E, Prenzel N and Ullrich A: Epidermal growth factor receptors: critical mediators of multiple receptor pathways. Curr Opin Cell Biol 11: 184-189, 1999.

27. Zwick E, Hackel PO, Prenzel N and Ullrich A: The EGF receptor as central transducer of heterologous signalling systems. Trends Pharmacol Sci 20: 408-412, 1999.

28. Mifune M, Ohtsu H, Suzuki H, et al: Signal transduction of betacellulin in growth and migration of vascular smooth muscle cells. Am J Physiol Cell Physiol 287: C807-C813, 2004.

29. Kazumori H, Ishihara S, Fukuda R and Kinoshita Y: Timecourse changes of ECL cell markers in acetic acid-induced gastric ulcers in rats. Aliment Pharmacol Ther 16 (Suppl 2): 10-19, 2002 . 